\title{
Reevaluation of bactericidal, cytotoxic, and macrophage-stimulating activities of commercially available Fucus vesiculosus fucoidan
}

\author{
Tomoki Nishiguchi ${ }^{1}$, Zedong Jiang ${ }^{1}$, Mikinori Ueno ${ }^{1}$, Satoshi Takeshita ${ }^{2}$ Kichul Cho $^{3,4}$, \\ Seong Woon Roh $^{4}$, Kyong-Hwa Kang ${ }^{5}$, Kenichi Yamaguchi ${ }^{1,6}$, Daekyung Kim ${ }^{3,4}$ and \\ Tatsuya Oda ${ }^{1,6, *}$
}

\author{
${ }^{1}$ Graduate School of Fisheries Science and Environmental Studies, Nagasaki University, 1-14 Bunkyo-machi, Nagasaki, \\ Nagasaki 852-8521, Japan \\ ${ }^{2}$ Joint Research Division, Center for Industry, University and Government Cooperation, Nagasaki University, 1-14 \\ Bunkyo-machi, Nagasaki, Nagasaki 852-8521, Japan \\ ${ }^{3}$ Korea University of Science and Technology, Daejeon 305-350, Korea \\ ${ }^{4}$ Jeju Center, Korea Basic Science Institute (KBSI), Jeju 690-756, Korea \\ ${ }^{5}$ Department of Chemistry, Pukyong National University, Busan 608-737, Korea \\ ${ }^{6}$ Division of Biochemistry, Faculty of Fisheries, Nagasaki University, 1-14 Bunkyo-machi, Nagasaki, Nagasaki 852-8521, \\ Japan
}

Polysaccharides prepared from marine algae sometimes contain contaminants such as polyphenols and endotoxins that may mislead their bona fide biological activities. In this study, we examined bioactive contaminants in commercially available fucoindan from Fucus vesiculosus, along with ascophyllan and fucoidan from Ascophyllum nodosum. F. vesiculosus fucoidan inhibited the growth of Vibrio alginolyticus in a concentration-dependent manner $\left(0-1,000 \mu \mathrm{g} \mathrm{mL}{ }^{-1}\right)$. However, the antibacterial activity of the fucoidan significantly reduced after methanol-extraction, and the methanol-extract showed a potent antibacterial activity. The extract also showed cytotoxicity to RAW264.7 and U937 cells, and induced apoptotic nuclear morphological changes in U937 cells. These results suggest that the antibacterial activity of the fucoidan is partly due to the methanol-extractable contaminants that can also contribute to the cytotoxicity on RAW264.7 and U937 cells. On the other hand, the activities to induce secretion of nitric oxide and tumor necrosis factor- $\alpha$ from RAW264.7 cells were observed in the fucoidan even after methanol extraction, and the extract had no such activities. Our observations suggest that commercially available fucoidan should be purified prior to biochemical use.

Key Words: antibacterial activity; contaminants; cytotoxic activity; Fucus vesiculosus; fucoidan

\section{INTRODUCTION}

Algal polysaccharides such as alginate, fucoidan, carrageenan, laminaran, and agar have recently been drawing a great attention from diverse research fields to develop as new biomaterials, health foods, or supplements.
Some of these polysaccharides show antitumor (Noda et al. 1990, Lins et al. 2009, Wang et al. 2010), antiviral (Witvrouw and De Clercq 1997, Damonte et al. 2004), anticomplementary (Tissot and Daniel 2003, Clément et
(9) $\$$ This is an Open Access article distributed under the terms of the Creative Commons Attribution Non-Commercial License (http://creativecommons.org/licenses/by-nc/3.0/) which permits unrestricted non-commercial use, distribution, and reproduction in any medium, provided the original work is properly cited.
Received May 1, 2014, Accepted September 2, 2014

* Corresponding Author

E-mail: t-oda@nagasaki-u.ac.jp

Tel: +81-95-819-2831, Fax: +81-95-819-2799 
al. 2010), anticoagulant (Pereira et al. 1999, Kusaykin et al. 2008), antioxidant (De Souza et al. 2007, Costa et al. 2010), anti-inflammatory (Kang et al. 2011), and immuno-modulatory (Leiro et al. 2007) activities. Brown algae such as Fucus vesiculosus, Ascophyllum nodosum, and Laminaria angustata are often used as raw materials for the preparation of alginate, laminaran, and fucoidan. Fucoidan is basically a sulfated fucan containing sulfated fucose as a main component and sometimes containing uronic acids, galactose, and xylose as minor compositions depending on algae species (Medcalf and Larsen 1977). Structural characterization of sulfated polysaccharide fractions prepared from $F$. vesiculosus suggested the existence of different types of sulfated polysaccharides distinguished from fucoidans (Nishino et al. 1994). Previous study demonstrated that ascophyllan could be (xylofucoglycuronan) isolated from the brown alga A. nodosum as a separated fraction from fucoidan (Kloareg et al. 1986). Besides some structural and bioactive similarities between fucoidan and ascophyllan (Heinzelmann et al. 1998, Nakayasu et al. 2009), our previous study demonstrated that ascophyllan showed a growth-promoting activity on MDCK cells, while fucoidan was rather toxic to this cell line (Jiang et al. 2010). During the course of our comparative studies on the cellular level biological activities of sulfated polysaccharides from different seaweed species, we found that $F$ vesiculosus fucoidan, which is the only commercially available one, was highly cytotoxic to RAW264.7 cells, whereas ascophyllan and fucoidan isolated from A. nodosum showed no significant cytotoxicity on RAW264.7 cells up to $1,000 \mu \mathrm{gL}^{-1}$ (Jiang et al. 2011).

Fucoidans isolated from several algal species including commercially available fucoidan have been reported to possess numerous biological activities such as anticoagulant (Pereira et al. 1999), antithrombotic activities (Kusaykin et al. 2008), antiviral (Karmakar et al. 2010, Sinha et al. 2010), antitumor, anti-inflammatory (Cumashi et al. 2007, Croci et al. 2011), immuno-modulatory (Raghavendran et al. 2011), and apoptosis-inducing activities (Jin et al. 2010, Kim et al. 2010). In addition to these biological activities in mammalian systems, fucoidan was found to be capable of affecting certain bacterial species. It has been reported that fucoidan extracted from Cladosiphon okamuranus inhibited the adhesion of Helicobacter pylo$r i$ to human gastric cells through coating the H. pylori cell surface (Shibata et al. 1999). Similar activity was also observed in commercially available fucoidan from $\mathrm{F}$ vesiculosus (Shibata et al. 1999). Several other studies reported that seaweed-derived polysaccharides showed direct antibacterial activities. For instance, crude fucoidan ex- tracted from Sargassum polycystum inhibited the growth of Vibrio harveyi, Staphylococcus aureus, and Escherichia coli at minimal inhibition concentrations (MIC) of 12.0, 12.0, and $6.0 \mathrm{mg} \mathrm{mL}^{-1}$, respectively (Chotigeat et al. 2004). Sulfated galactan with a molecular weight of $1,160 \mathrm{kDa}$ extracted from marine alga Chaetomorpha aerea exhibited selective antibacterial activities against Bacillus subtilis, Micrococcus luteus, and S. aureus (Pierre et al. 2011). Polysaccharides prepared from Laminaria japonica showed antibacterial activities against $E$. coli and $S$. aureus (Li et al. 2010). These findings suggest that some sulfated polysaccharides including fucoidan have antibacterial activity, although the purity and the exact action mechanism remain to be clarified. To address how the algal source of fucoidan could associate with antibacterial activity, we first investigated antibacterial activities of commercially available $F$. vesiculosus fucoidan, along with ascophyllan and fucoidan isolated from $A$. nodosum.

Since only the F. vesiculosus fucoidan among these polysaccharides showed antibacterial activity, we then examined the antibacterial and cytotoxic activities after fractionation of the fucoidan with methanol-extraction, confirming such activities have derived from methanolextractable impurities. In agreement with previous reports, methanol insoluble fraction containing fucoidan stimulated RAW264.7 cells inducing nitric oxide (NO) and tumor necrosis factor- $\alpha$ (TNF- $\alpha$ ), whereas methanol extractable fraction showed no such activities. Accordingly, we recommend commercially available fucoidan should be more purified before biochemical use to avoid misleading of its biological activities.

\section{MATERIALS AND METHODS}

Fucoidan isolated from $F$ vesiculosus was purchased from Sigma-Aldrich, Co. (St. Louis, MO, USA), and used without further purification. In this study, we mainly used fucoidan with Lot No. 066K3786 and basically the same results were obtained with fucoidan with different Lot No. 081M7672. Ascophyllan and fucoidan were prepared from powdered A. nodosum as described previously (Nakayasu et al. 2009). To distinguish two fucoidans with different origins, fucoidans from $F$. vesiculosus and A. nodosum were abbreviated as F-fucoidan and A-fucoidan, respectively. Polysaccharide sample solutions in phosphate buffered saline (PBS) were passed through cellulose acetate filter with pore size of $0.20 \mu \mathrm{m}$ (ADVANTEC, Tokyo, Japan) for sterilization before use. 3-[4,5-dimethylthiazol-2-yl]-2,5-diphenyltetrazolium bromide (MTT) 
was purchased from Sigma-Aldrich, Co. Alamar blue (AB) reagent was obtained from Life Technologies, Co. (Carlsbad, CA, USA). Other chemicals were of the highest grade commercially available.

\section{Preparation of methanol-extract and methanol- insoluble fraction of F-fucoidan}

Ten mg of F-fucoidan was suspended in $1 \mathrm{~mL}$ of methanol, and the mixture was stirred for $24 \mathrm{~h}$ at room temperature. Methanol-insoluble fraction and supernatant were separated by centrifugation $(2,000 \times \mathrm{g}, 5 \mathrm{~min})$. The supernatant (methanol-extract) and the methanol-insoluble fraction were dried up with centrifugal vacuum concentrator (SPD131DDA; Thermo Electron Co., Milford, MA, USA). About $0.68 \mathrm{mg}$ of the methanol extract as dried powder was obtained from $10 \mathrm{mg}$ of F-fucoidan.

\section{Antibacterial activity}

V. alginolyticus (NBRC15630) from NITE Biological Resource Center (Chiba, Japan) and E. coli (JCM5491) and $S$. aureus (JCM2413) from RIKEN Biological Resource Center (Tsukuba, Japan) were used as test microorganisms. $V$. alginolyticus was cultured in marine agar or marine broth at $26^{\circ} \mathrm{C}$, and E. coli and S. aureus were cultured in nutrient agar or nutrient broth at $37^{\circ} \mathrm{C}$. Antibacterial activities of test samples on V. alginolyticus were evaluated by AB assay (Ahmed et al. 1994). AB reagent is a metabolic indicator, and as consequence of bacterial growth, the color of the $\mathrm{AB}$ reagent is changed from blue to pink. It has been confirmed that the classical colony formation assay and $\mathrm{AB}$ assay are comparable to evaluate bacterial viability (Collins and Franzblau 1997). The bacteria were precultured in marine broth at $26^{\circ} \mathrm{C}$ overnight, and harvested by centrifugation $(1,500 \times \mathrm{g})$. The cells were washed twice with PBS by centrifugation $(1,500 \times \mathrm{g})$ and the cell pellets were resuspended in PBS (final cell density of $10^{7}$ $\mathrm{CFU} \mathrm{mL} \mathrm{m}^{-1}$ ), and incubated with varying concentrations of each sample at $26^{\circ} \mathrm{C}$ for $24 \mathrm{~h}$ in a 96-well flat-bottompolystyrene microplate $\left(100 \mu \mathrm{L}\right.$ well $\left.{ }^{-1}\right)$ with shaking. PBS alone was used as the sample blank. After the addition of $10 \mu \mathrm{L}$ of $\mathrm{AB}$ reagent to each well, the plate was incubated at $26^{\circ} \mathrm{C}$ for further $4 \mathrm{~h}$, and then the optical density of the well at 570-600 nm was immediately recorded with a multiwell scanning spectrophotometer (Multiskan Spectrum; Thermo Electron Co., Vantaa, Finland). The blank value was subtracted from all the values as a background. For the measurement of viable bacterial cell numbers in the reaction mixture, colony formation assay was also con- ducted. In the assay, aliquot of $10 \mu \mathrm{L}$ from each reaction mixture was withdrawn and inoculated into marine agaror nutrient agar-medium after appropriate dilution with PBS, and cultured at 26 or $37^{\circ} \mathrm{C}$ for $24 \mathrm{~h}$ for colony formation.

\section{Cell culture}

RAW264.7 (mouse macrophage) cells obtained from the American Type Culture Collection (Rockville, MD, USA) were cultured at $37^{\circ} \mathrm{C}$ in Dulbecco's modified Eagle's minimum essential medium (DMEM) supplemented with $10 \%$ fetal bovine serum (FBS), penicillin (100 IU $\left.\mathrm{mL}^{-1}\right)$, and streptomycin $\left(100 \mu \mathrm{g} \mathrm{mL} \mathrm{m}^{-1}\right)$ in a humidified atmosphere with $5 \% \mathrm{CO}_{2}$ and $95 \%$ air. Human myeloid leukemia U937 cells obtained from RIKEN Cell Bank (Tsukuba, Japan) were cultured at $37^{\circ} \mathrm{C}$ in RPMI1640 medium (Gibco, Gaithersburg, MD, USA) supplemented with $10 \%$ FBS in a humidified atmosphere of $5 \% \mathrm{CO}_{2}$ and $95 \%$ air.

\section{Cytotoxicity}

Cytotoxicity of test samples on RAW264.7 cells was measured by MTT tetrazolium cytotoxicity assay. In brief, adherent cells $\left(3 \times 10^{4}\right.$ cells well $\left.^{-1}\right)$ in a 96-well plate were cultured with varying concentrations of each sample in DMEM for $24 \mathrm{~h}$, and then incubated with MTT (final 10\%) for $20 \mathrm{~min}$. After aspiration of the medium, dimethylsulfoxide was added to dissolve the MTT formazan reaction product and the optical density was measured at $535 \mathrm{~nm}$ using a multiwell scanning spectrophotometer. Cytotoxicity of test samples on U937 cells was measured by AB assay as described previously (Koyanagi et al. 2003). In brief, $2 \times 10^{4}$ cells per well in a 96-well plate were cultured with varying concentrations of samples in the growth medium for $24 \mathrm{~h}$, and then $\mathrm{AB}$ reagent (final $10 \%$ ) was added to each well. After $2 \mathrm{~h}$ incubation at $37^{\circ} \mathrm{C}$, the optical density of each well at 570-600 $\mathrm{nm}$ was measured with a multiwell scanning spectrophotometer.

\section{Nuclear staining}

Nuclear morphological changes in U937 cells treated with test samples were examined by staining with DNAbinding fluorochrome bisbenzimide (Hoechst 33342; Dojindo Laboratories, Kumamoto, Japan) as described previously (Nakayasu et al. 2009). In brief, cells in 96 -well plates $\left(2 \times 10^{5}\right.$ cells well $\left.^{-1}\right)$ were incubated with indicated concentrations of each sample in the growth medium at $37^{\circ} \mathrm{C}$, and then Hoechst 33342 (final $10 \mu \mathrm{g} \mathrm{mL}^{-1}$ ) was 
added to the treated cells. After $5 \mathrm{~min}$ incubation at $37^{\circ} \mathrm{C}$, the cells were observed by fluorescence microscope (Axiovert 200; Carl Zeiss, Inc., Jena, Germany). Cells with apoptotic nuclei, i.e., condensed or fragmented, emitting a higher intensity of fluorescence compared with normal cells, were considered as apoptotic cells. At least 100 cells at different areas were observed for each treated group to estimate $\%$ of apoptotic cell population.

\section{Nitrite assay for the estimation of nitric oxide (NO)}

To estimate NO level in RAW264.7 cells, nitrite, a stable reaction product of NO with molecular oxygen, was measured by Griess assay as described previously (Jiang et al. 2011). In brief, adherent RAW264.7 cells in 96-well plates $\left(3 \times 10^{4}\right.$ cells well $\left.^{-1}\right)$ were incubated with varying concentrations of test samples for $24 \mathrm{~h}$ in the growth medium at $37^{\circ} \mathrm{C}$, and then the nitrite levels in the culture medium were measured.

\section{Enzyme-linked immunosorbent assay (ELISA)}

Adherent RAW264.7 cells in 96-well plates $\left(3 \times 10^{4}\right.$ cells well ${ }^{-1}$ ) were treated with varying concentrations of test samples in the growth medium at $37^{\circ} \mathrm{C}$. After $24 \mathrm{~h}$ incubation, the levels of TNF- $\alpha$ in the culture supernatants of treated cells were measured by sandwich ELISA with two antibodies to two different epitopes on TNF- $\alpha$ molecule as described previously (Jiang et al. 2011). The TNF- $\alpha$ concentrations were estimated from a reference to a standard curve for serial three-fold dilution of murine recombinant TNF- $\alpha$.

\section{Element analysis}

For the analysis of carbon, hydrogen, nitrogen, sulfur and oxygen content in the methanol-extract, we used PerkinElmer 2400 Series II CHNS/O elemental analyzer (PerkinElmer, Waltham, MA, USA) according to the manufacture's instruction. Energy-dispersive X-ray detector (EDS) equipped in scanning electron microscope (JEOL JSM-7500F; JEOL Ltd., Tokyo, Japan) was used for further elemental composition investigation of the methanolextract.

\section{Assay for phenolic compounds}

The detection of phenolic compounds in the methanol-extract was carried out by the Folin-Denis method (Niwano et al. 2007). In brief, $3.2 \mathrm{~mL}$ of distilled water, 0.2
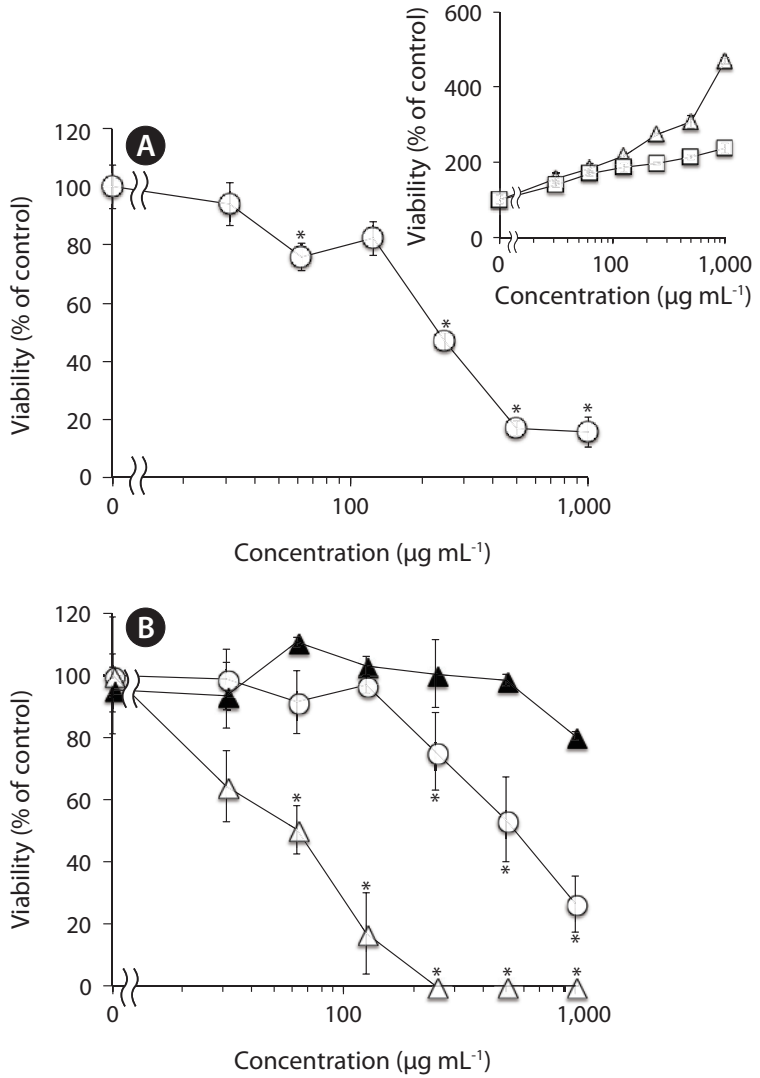

Fig. 1. Effects of polysaccharides on Vibrio alginolyticus. (A) Effects of F-fucoidan ( $(\circ)$, A-fucoidan $(\Delta)$, and ascophyllan ( $\square$ ) on V. alginolyticus as measured by Alamar blue assay. (B) Effects of methanol-extraction on the antibacterial activity of F-fucoidan $(0)$, the methanol-extract $(\Delta)$, and the methanol-insoluble residual fraction $(\boldsymbol{\Delta})$ toward $V$. alginolyticus by Alamar blue assay. Data represent the average of triplicate measurements and bars indicate the standard deviation. Asterisks indicate significant differences between with and without polysaccharide samples $(p<0.01)$.

$\mathrm{mL}$ of each sample solution or distilled water as a solvent, $0.2 \mathrm{~mL}$ of Folin and Ciocalteu's phenol reagent, and 0.4 $\mathrm{mL}$ of saturated sodium carbonate solution were mixed. The absorbance was read at $760 \mathrm{~nm}$ after $30 \mathrm{~min}$ incubation at room temperature.

\section{Statistical analysis}

All the experiments were repeated at least three times. Data were expressed as means \pm standard deviation (SD). Tested groups were compared with appropriate controls using the Student's t-test. Differences were considered significant at $\mathrm{p}<0.01$ 


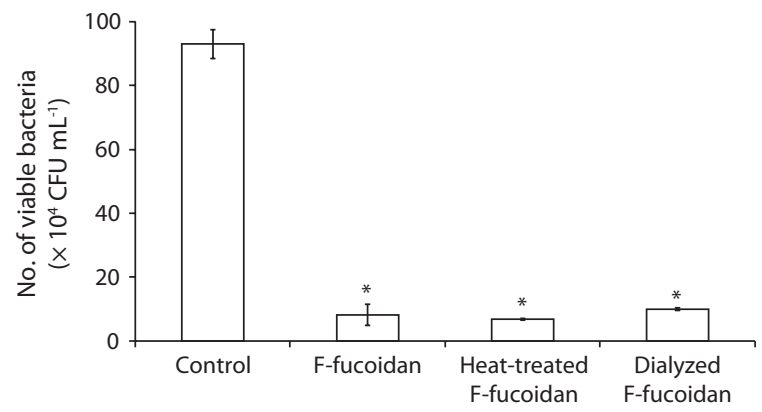

Fig. 2. Effects of heat-treatment and dialysis on the antibacterial activity of F-fucoidan on Vibrio alginolyticus as measured by colony formation assay. The data represent the average of triplicate measurements and the bars indicate the standard deviation. Asterisks indicate significant differences between with and without test samples $(p<0.01)$.

\section{RESULTS}

\section{Antibacterial activities of polysaccharide samples}

Antibacterial activities of F-fucoidan, A-fucoidan, and ascophyllan were assayed by $\mathrm{AB}$ assay using $V$. alginolyticus as a test bacterium. As shown in Fig. 1A, F-fucoidan showed antibacterial activity in a concentration-dependent manner, whereas A-fucoidan and ascophyllan exhibited even growth-promoting effects on V.alginolyticus rather than the growth inhibition. Since the antibacterial assays were conducted in PBS, it is considered that A-fucoidan and ascophyllan might be assimilated with the bacteria as nutrients, and that may lead to the growth promotion.

\section{Effects of methanol-extraction on the antibacte- rial activities of F-fucoidan}

Since it has been reported that antibacterial activities were found in organic extracts of $F$. vesiculosus (Lustig- man and Brown 1991), we prepared methanol extract from F-fucoidan, and examined its antibacterial activities together with the methanol-insoluble residual fraction and original F-fucoidan toward V. alginolyticus. As shown in Fig. 1B, the extract exhibited a potent antibacterial activity that was even greater than original F-fucoidan. The methanol-insoluble fraction showed only a trace level antibacterial activity even at $1,000 \mu \mathrm{g} \mathrm{mL}^{-1}$. These results suggest that methanol-extractable contaminants in F-fucoidan are mainly responsible for the antibacterial activity of F-fucoidan.

\section{Species-specificity of the antibacterial activities of F-fucoidan, the methanol-extract, and the methanol-insoluble residual fraction prepared from F-fucoidan}

To characterize the antibacterial activities of F-fucoidan, the effects of F-fucoidan on E. coli and S. aureus in addition to V.alginolyticus were examined by colony formation assay. As shown in Table 1, antibacterial activity of F-fucoidan was species-specific, and the susceptibility of V. alginolyticus to F-fucoidan was the highest. E. coli and $S$. aureus showed nearly similar sensitivity to F-fucoidan. Extremely greater antibacterial activities of the methanolextract than F-fucoidan on these bacteria were observed, whereas the activity of the methanol-insoluble residual fraction was very low.

\section{Partial characterization of the antibacterial ac- tivity of F-fucoidan}

After dialysis of $\mathrm{F}$-fucoidan with molecular porous membrane tube (MWCO; 6,000-8,000) against distilled water for 3 days, the contents inside the tube were lyophilized. As shown in Fig. 2, this simple dialysis of F-fucoidan could not remove the activity. Hence, the antibacterial

Table 1. Antibacterial activities of F-fucoidan, the methanol-insoluble fraction, and the methanol-extract on Vibrio alginolyticus, Escherichia coli, and Staphylococcus aureus as measured by colony formation assay

\begin{tabular}{|c|c|c|c|}
\hline & \multicolumn{3}{|c|}{ Unit $\left.\left(\times 10^{6}, \mathrm{CFU} \mathrm{mL}\right)^{-1}\right)^{\mathrm{a}}$} \\
\hline & V.alginolyticus & E. coli & S.aureus \\
\hline PBS alone & $6.2 \pm 0.3$ & $8.7 \pm 0.5$ & $5.8 \pm 0.1$ \\
\hline + F-fucoidan & $0.056 \pm 0.004$ & $2.5 \pm 0.2$ & $1.6 \pm 0.09$ \\
\hline + Methanol-insoluble fraction & $1.2 \pm 0.1$ & $7.8 \pm 0.5$ & $2.2 \pm 0.03$ \\
\hline + Methanol-extract & $0 \pm 0$ & $0 \pm 0$ & $0.057 \pm 0.0001$ \\
\hline
\end{tabular}

${ }^{a}$ After $24 \mathrm{~h}$ incubation at $26^{\circ} \mathrm{C}$ for V. alginolyticus or $37^{\circ} \mathrm{C}$ for $E$. coli and S. aureus in phosphate buffered saline (PBS) in the presence of $1,000 \mu \mathrm{g} \mathrm{mL}$ of each sample, the values of colony forming unit (CFU) of the treated bacteria were measured as described in the text. 
agents in F-fucoidan may form relatively tight complex with fucoidan molecule through a hydrophobic interaction. After treatment of F-fucoidan at $121^{\circ} \mathrm{C}$ for $30 \mathrm{~min}$, no significant reduction of the antibacterial activity was observed (Fig. 2). Furthermore, nearly 99\% of antibacterial activity of the methanol-extract passed through the filter that can cut molecules with higher than 3,000 kDa (data not shown). These results suggest that antibacterial agents in F-fucoidan are low molecular weight heat-stable compounds.

\section{Chemical composition analysis of the methanol- extract}

The results of chemical and element analysis of the methanol-extract were summarized in Table 2. Since more than $95 \%$ of the methanol-extract were occupied with $\mathrm{Na}, \mathrm{Cl}, \mathrm{K}$, and $\mathrm{Si}$, the main ingredients of the methanol-extract are considered to be inorganic compounds such as $\mathrm{NaCl}$, and organic compounds were estimated to be only about $3 \%(\mathrm{w} / \mathrm{w})$. Phenolic compounds in the methanol-extract were detected by Folin-Denis method, and the amount was estimated to be less than $1 \%$ of the total weight of the extract.

\section{Cytotoxic effects of F-fucoidan, the methanol- extract, and the methanol-insoluble fraction on RAW264.7 cells and U937 cells}

We have previously reported that F-fucoidan, but not A-fucoidan and ascophyllan, showed cytotoxic effect on RAW264.7 cells (Jiang et al. 2011). To investigate the involvement of the methanol-extractable agents of F-fucoidan in the cytotoxicity of F-fucoidan, we examined the

Table 2. Chemical composition analysis of the methanol-extract of F-fucoidan

\begin{tabular}{cc}
\hline Element & mg g $^{-1}(\%)$ \\
\hline $\mathrm{Cl}$ & $605.1(60.5)^{\mathrm{a}}$ \\
$\mathrm{Na}$ & $309.8(31.0)^{\mathrm{a}}$ \\
$\mathrm{K}$ & $27.9(2.8)^{\mathrm{a}}$ \\
$\mathrm{Si}$ & $19.4(1.9)^{\mathrm{a}}$ \\
$\mathrm{C}$ & $30.7(3.1)^{\mathrm{b}}$ \\
$\mathrm{H}$ & $3.7(0.4)^{\mathrm{b}}$ \\
$\mathrm{N}$ & $3.5(0.4)^{\mathrm{b}}$ \\
Phenolic compounds & $6.8 \pm 1.0(0.7)^{\mathrm{c}}$ \\
\hline
\end{tabular}

${ }^{a}$ Data were obtained by energy-dispersive X-ray detector analysis.

${ }^{b}$ Data were obtained with CHNS/O elemental analyzer.

'The value was estimated by the Folin-Denis method.
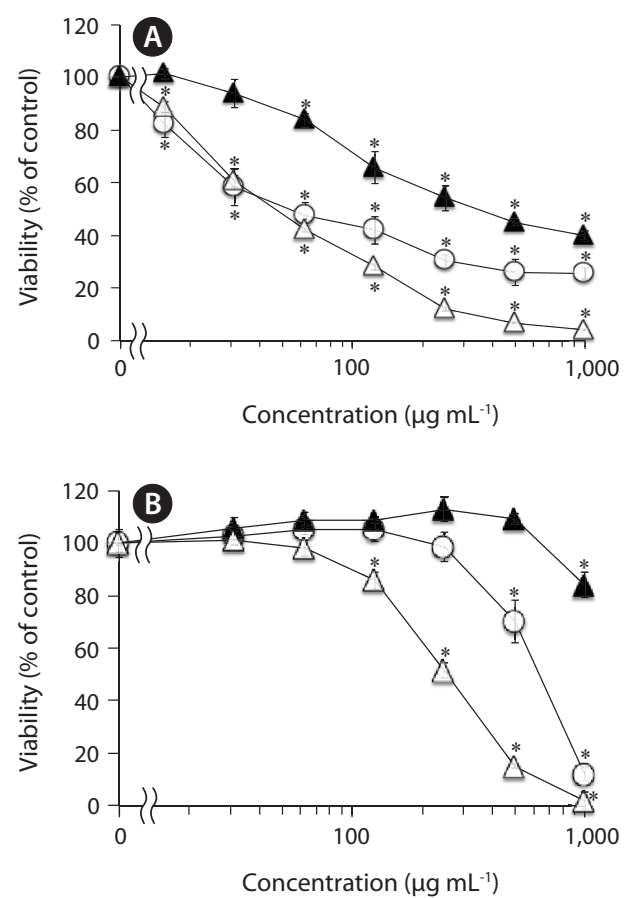

Fig. 3. Cytotoxic effects of F-fucoidan, the methanol-extract, and the methanol-insoluble fraction on RAW264.7 and U937 cells. (A) MTT assay of varying concentrations of F-fucoidan (०), the methanolextract $(\Delta)$, or the methanol-insoluble fraction $(\boldsymbol{\Delta})$ on RAW264.7 cells. (B) Alamar blue assay of U937 cells treated with varying concentrations of F-fucoidan $(0)$, the methanol-extract $(\Delta)$, or the methanol-insoluble fraction ( $\boldsymbol{\Delta})$. Data represent the average of triplicate measurements and the bars indicate standard deviations. Asterisks indicate significant differences between with and without test samples $(p<0.01)$.

cytotoxic effects of the extract and the residual methanolinsoluble fraction of F-fucoidan on RAW264.7 and U937 cells. As shown in Fig. 3A, the methanol-extract showed stronger cytotoxicity on RAW264.7 cells than original Ffucoidan, and the activity of the methanol-insoluble fraction was lower than the original F-fucoidan. The extract also showed a potent cytotoxic effect on U937 cells (Fig. 3B), and nuclear staining revealed that the extract was capable of inducing typical apoptotic nuclear morphological changes in U937 cells in a concentration-dependent manner (Fig. 4A-E). Much greater population of U937 cells treated with the methanol-extract showed such apoptotic nuclear changes than the cells treated with original F-fucoidan. The activity of the methanol-insoluble fraction to induce apoptotic nuclear morphological changes was obviously lower than that of original F-fucoidan, and only a few apoptotic cells were observed in the U937 cells treated with the methanol-insoluble fraction. Time-course analysis of the nuclear morphological changes revealed that the extract induced the apoptotic 

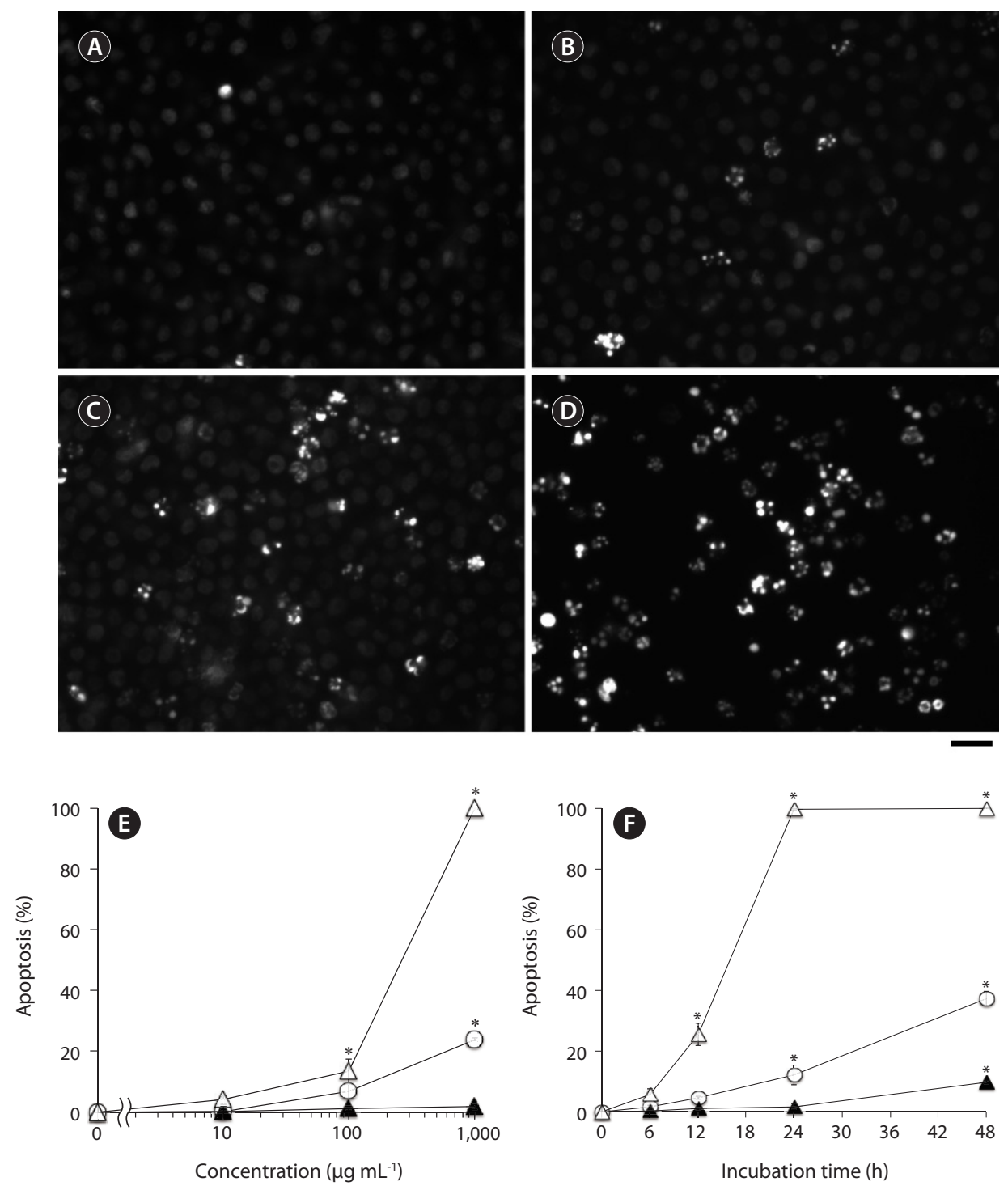

Fig. 4. Nuclear morphological changes in U937 cells treated with F-fucoidan, the methanol-extract, or the methanol-insoluble fraction. (AD) Nuclear morphological changes in U937 cells treated with medium alone (A) or with the methanol-insoluble fraction (B), F-fucoidan (C), or the methanol-extract (D) stained cells observed by a fluorescent microscope. (E) U937 cells were incubated with indicated concentrations of F-fucoidan ( $(\circ)$, the methanol-extract $(\Delta)$, or the methanol-insoluble fraction $(\mathbf{\Delta})$ for $24 \mathrm{~h}$ at $37^{\circ} \mathrm{C}$. The populations of the cells with apoptotic nuclear morphological changes were scored as described in the text. (F) U937 cells were incubated with 1,000 $\mu \mathrm{g} \mathrm{mL} \mathrm{L}^{-1}$ of F-fucoidan (o), the methanol-extract $(\Delta)$, or the methanol-insoluble fraction $(\boldsymbol{\Delta})$ for the indicated periods of time at $37^{\circ} \mathrm{C}$ and the populations of the cells with apoptotic nuclear morphological changes were scored as described in the text. Data represent the average of triplicate measurements and the bars indicate standard deviations. Asterisks indicate significant differences between with and without test samples $(p<0.01)$. Scale bar represents: A-D, $20 \mu \mathrm{m}$.

changes in U937 cells with much earlier time schedule than F-fucoidan, suggesting that underlying apoptosisinducing mechanisms of the extract and F-fucoidan might be different (Fig. 4F).

\section{NO- and TNF-a-inducing activities of F-fucoidan, the methanol-extract, and the methanol-insolu- ble fraction in RAW264.7 cells}

Fucoidans including commercially available $F$. vesiculosus fucoidan are known to induce secretion of NO and cytokines from RAW264.7 cells (Jiang et al. 2011). We investigated whether or not the methanol-extract is involved in such activities of F-fucoidan. As shown in Fig. 5 , the extract showed no significant NO- and TNF- $\alpha$ inducing activities, whereas the methanol-insoluble residual fraction exhibited the activities with almost equal 

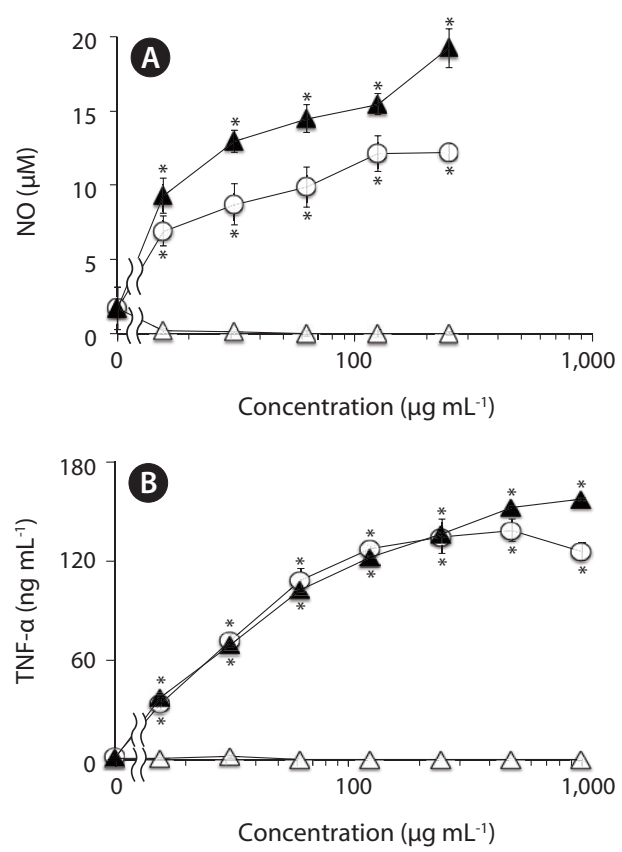

Fig. 5. Nitric oxide (NO)- and tumor necrosis factor-a (TNF-a)inducing activities of F-fucoidan, the methanol-extract, and the methanol-insoluble fraction in RAW264.7 cells. Adherent RAW264.7 cells were incubated with varying concentrations of F-fucoidan (O), the methanol-extract $(\Delta)$, or the methanol-insoluble fraction $(\boldsymbol{A})$. (A) The NO levels in the culture medium from the treated cells were estimated by Griess assay. (B) The levels of TNF-a in the culture supernatants of the treated cells were measured by enzyme-linked immunosorbent assay as described in the text. Data represent the average of triplicate measurements and the bars indicate standard deviations. Asterisks indicate significant differences between with and without test samples $(p<0.01)$.

to original F-fucoidan. These results clearly indicate that the extract does not contribute to macrophage-stimulating activity of the F-fucoidan, suggesting that the macrophage-stimulating activity of F-fucoidan is attributed to sulfated polysaccharide in F-fucoidan as a main component.

\section{DISCUSSION}

It has been reported that the fucoidan extracted from $S$. polycystum showed antibacterial activity against $V$. harveyi, S. aureus, and E. coli at the MIC of 12.0, 12.0, and $6.0 \mathrm{mg} \mathrm{mL}^{-1}$, respectively. However, these concentrations seem to be quite higher as compared to other study in which $L$. japonica polysaccharides showed antibacterial activities against $S$. aureus and E. coli at the MIC of 0.21 and $0.34 \mathrm{mg} \mathrm{mL}^{-1}$, respectively. Since antibacterial activities have also been found in organic extracts of $F$. vesiculosus (Lustigman and Brown 1991), it is uncertain whether or not sulfated polysaccharides especially $F$ vesiculosus fucoidan indeed have antibacterial activities or it is due to the contamination in sulfated polysaccharides. To gain insight into this point, we investigated the antibacterial activities of ascophyllan and two fucoidans derived from A. nodusum (A-fucoidan) and F. vesiculosus (F-fucoidan). The results indicated that only the F-fucoidan showed growth inhibitory effect on $V$. alginolyticus in a concentration-dependent manner with $500 \mu \mathrm{gL}^{-1}$ of MIC, and the activity was significantly reduced by methanol-extraction. Furthermore, the methanol-extract showed even stronger antibacterial activity than original F-fucoidan, suggesting that the most part of antibacterial activity of F-fucoidan is derived from non-polysaccharide contaminants. Although the bioactivities of algal polysaccharides differ depending on the compositions, the entire structures, and the physicochemical properties (Baba et al. 1990, Ellouali et al. 1993), at least ascophyllan and Afucoidan showed no significant growth-inhibitory effect on V. alginolyticus up to $1,000 \mu \mathrm{gL}^{-1}$. Based on our results, we propose that at least the process of methanolextraction should be conducted on commercially available $F$ vesiculosus fucoidan to avoid misleading of its biological activity.

Moreover, the methanol-extract prepared from Ffucoidan exhibit much stronger cytotoxic effects on RAW264.7 and U937 cells than original F-fucoidan, while the cytotoxicities of F-fucoidan decreased after methanol-extraction. Further study showed that the extract was capable of inducing apoptotic nuclear morphological changes in U937 cells. Time-course analysis on the appearances of apoptotic cells showed that the kinetics of the extract to induce apoptosis might differ from that of original F-fucoidan. In other words, F-fucoidan may be contaminated with apoptosis-inducing agents that have a distinct action mechanism from fucoidan itself. The cytotoxicity and apoptosis-inducing activity of F-fucoidan on U937 cells could not completely be eliminated by methanol-extraction.

Partial chemical characterization suggested that the agents responsible for the antibacterial activity in the methanol-extract were low molecular weight heat-stable compounds. Element analysis suggested the methanol-extract contains phenolic compounds in addition to inorganic compounds such as $\mathrm{NaCl}$. It has been reported that phenolic compounds such as phlorotannins present in brown algae showed antibacterial activities against Gram-positive and Gram-negative bacteria with relatively broad antibacterial spectrum (Nagayama et al. 2002). Similar to phlorotannins, the methanol-extract of 
F-fucoidan showed significant antibacterial activities on S. aureus and E. coli in addition to V. alginolyticus. Furthermore, apoptosis-inducing activity of phlorotannins has been reported (Yoon et al. 2013). Hence, one possible candidate for the antibacterial and cytotoxic agents in the methanol-extract are phenolic compounds, although further studies are required to identify and characterize these agents responsible for these activities.

In addition, the methanol-insoluble residual fraction of F-fucoidan exhibited the activities to induce NO and TNF- $\alpha$ from RAW264.7 cells with almost similar concentration-dependent profile to the original F-fucoidan, while the methanol-extract showed no significant activities over the concentration range $\left(0-1,000 \mu \mathrm{gLL}^{-1}\right)$ tested, suggesting that the macrophage-stimulating activities of F-fucoidan are mainly attributed to sulfated polysaccharide as a main component.

In conclusion, the results obtained in this study suggested that commercially available $F$. vesiculosus fucoidan is contaminated with methanol-extractable antibacterial and cytotoxic agents. Although the agents responsible for the toxicities in the methanol-extract could not be fully characterized yet, the methanol-extract showed a potent apoptosis-inducing activity on U937 cells, but had no activities to induce NO and TNF- $\alpha$ from RAW264.7 cells. Hence, it should be careful when it comes to the studies on the cytotoxic and apoptosis-inducing activities of fucoidan especially the usage of commercially available $F$ vesiculosus fucoidan without further purification.

\section{ACKNOWLEDGEMENTS}

This work was supported in part by a Grant-in-Aid for Scientific Research from the Ministry of Education, Culture, Sports, Science and Technology of Japan and a Project fund (C34290) to D. Kim from Jeju Center at the Korea Basic Science Institute of Korea.

\section{REFERENCES}

Ahmed, S. A., Gogal, R. M. Jr. \& Walsh, J. E. 1994. A new rapid and simple non-radioactive assay to monitor and determine the proliferation of lymphocytes: an alternative to $\left[{ }^{3} \mathrm{H}\right]$ thymidine incorporation assay. J. Immunol. Methods 170:211-224.

Baba, M., Schols, D., Pauwels, R., Nakashima, H. \& De Clercq, E. 1990. Sulfated polysaccharides as potent inhibitors of HIV-induced syncytium formation: a new strategy towards AIDS chemotherapy. J. Acquir. Immune Defic. Syndr. 3:493-499.

Chotigeat, W., Tongsupa, S., Supamataya, K. \& Phongdara, A. 2004. Effect of fucoidan on disease resistance of black tiger shrimp. Aquaculture 233:23-30.

Clément, M. J., Tissot, B., Chevolot, L., Adjadj, E., Du, Y., Curmi, P. A. \& Daniel, R. 2010. NMR characterization and molecular modeling of fucoidan showing the importance of oligosaccharide branching in its anticomplementary activity. Glycobiology 20:883-894.

Collins, L. \& Franzblau, S. G. 1997. Microplate alamar blue assay versus BACTEC 460 system for high-throughput screening of compounds against Mycobacterium tuberculosis and Mycobacterium avium. Antimicrob. Agents Chemother. 41:1004-1009.

Costa, L. S., Fidelis, G. P., Cordeiro, S. L., Oliveira, R. M., Sabry, D. A., Câmara, R. B., Nobre, L. T., Costa, M. S., Almeida-Lima, J., Farias, E. H., Leite, E. L. \& Rocha, H. A. 2010. Biological activities of sulfated polysaccharides from tropical seaweeds. Biomed. Pharmacother. 64:21-28.

Croci, D. O., Cumashi, A., Ushakova, N. A., Preobrazhenskaya, M. E., Piccoli, A., Totani, L., Ustyuzhanina, N. E., Bilan, M. I., Usov, A. I., Grachev, A. A., Morozevich, G. E., Berman, A. E., Sanderson, C. J., Kelly, M., Di Gregorio, P., Rossi, C., Tinari, N., Iacobelli, S., Rabinovich, G. A., Nifantiev, N. E. \& Consorzio Interuniversitario Nazionale per la Bio-Oncologia (CINBO), Italy. 2011. Fucans, but not fucomannoglucuronans, determine the biological activities of sulfated polysaccharides from Laminaria saccharina brown seaweed. PLoS One 6:e17283.

Cumashi, A., Ushakova, N. A., Preobrazhenskaya, M. E., D’Incecco, A., Piccoli, A., Totani, L., Tinari, N., Morozevich, G. E., Berman, A. E., Bilan, M. I., Usov, A. I., Ustyuzhanina, N. E., Grachev, A. A., Sanderson, C. J., Kelly, M., Rabinovich, G. A., Iacobelli, S., Nifantiev, N. E. \& Consorzio Interuniversitario Nazionale per la Bio-Oncologia (CINBO), Italy. 2007. A comparative study of the anti-inflammatory, anticoagulant, antiangiogenic, and antiadhesive activities of nine different fucoidans from brown seaweeds. Glycobiology 17:541-552.

Damonte, E. B., Matulewicz, M. C. \& Cerezo, A. S. 2004. Sulfated seaweed polysaccharides as antiviral agents. Curr. Med. Chem. 11:2399-2419.

De Souza, M. C. R., Marques, C. T., Dore, C. M. G., Da Silva, F. R. F., Rocha, H. A. O. \& Leite, E. L. 2007. Antioxidant activities of sulfated polysaccharides from brown and red seaweeds. J. Appl. Phycol. 19:153-160.

Ellouali, M., Boisson-Vidal, C., Durand, P. \& Jozefonvicz, J. 1993. Antitumor activity of low molecular weight fucans extracted from brown seaweed Ascophyllum nodosum. 
Anticancer Res. 13:2011-2019.

Heinzelmann, M., Polk, H. C. Jr. \& Miller, F. N. 1998. Modulation of lipopolysaccharide-induced monocyte activation by heparin-binding protein and fucoidan. Infect. Immun. 66:5842-5847.

Jiang, Z., Okimura, T., Yamaguchi, K. \& Oda, T. 2011. The potent activity of sulfated polysaccharide, ascophyllan, isolated from Ascophyllum nodosum to induce nitric oxide and cytokine production from mouse macrophage RAW264.7 cells: comparison between ascophyllan and fucoidan. Nitric Oxide 25:407-415.

Jiang, Z., Okimura, T., Yokose, T., Yamasaki, Y., Yamaguchi, K. \& Oda, T. 2010. Effects of sulfated fucan, ascophyllan, from the brown alga Ascophyllum nodosum on various cell lines: a comparative study on ascophyllan and fucoidan. J. Biosci. Bioeng. 110:113-117.

Jin, J. -O., Song, M. -G., Kim, Y. -N., Park, J. -I. \& Kwak, J. -Y. 2010. The mechanism of fucoidan-induced apoptosis in leukemic cells: involvement of ERK1/2, JNK, glutathione, and nitric oxide. Mol. Carcinog. 49:771-782.

Kang, S. -M., Kim, K. -N., Lee, S. -H., Ahn, G., Cha, S. -H., Kim, A. -D., Yang, X. -D., Kang, M. -C. \& Jeon, Y. -J. 2011. Anti-inflammatory activity of polysaccharide purified from AMG-assistant extract of Ecklonia cava in LPSstimulated RAW 264.7 macrophages. Carbohydr. Polym. 85:80-85.

Karmakar, P., Pujol, C. A., Damonte, E. B., Ghosh, T. \& Ray, B. 2010. Polysaccharides from Padina tetrastromatica: structural features, chemical modification and antiviral activity. Carbohydr. Polym. 80:513-520.

Kim, E. J., Park, S. Y., Lee, J. -Y. \& Park, J. H. 2010. Fucoidan present in brown algae induces apoptosis of human colon cancer cells. BMC Gastroenterol. 10:96.

Kloareg, B., Demarty, M. \& Mabeau, S. 1986. Polyanionic characteristics of purified sulphated homofucans from brown algae. Int. J. Biol. Macromol. 8:380-386.

Koyanagi, S., Tanigawa, N., Nakagawa, H., Soeda, S. \& Shimeno, H. 2003. Oversulfation of fucoidan enhances its anti-angiogenic and antitumor activities. Biochem. Pharmacol. 65:173-179.

Kusaykin, M., Bakunina, I., Sova, V., Ermakova, S., Kuznetsova, T., Besednova, N., Zaporozhets, T. \& Zvyagintseva, T. 2008. Structure, biological activity, and enzymatic transformation of fucoidans from the brown seaweeds. Biotechnol. J. 3:904-915.

Leiro, J. M., Castro, R., Arranz, J. A. \& Lamas, J. 2007. Immunomodulating activities of acidic sulphated polysaccharides obtained from the seaweed Ulva rigida C. Agardh. Int. Immunopharmacol. 7:879-888.

Li, L. -Y., Li, L. -Q. \& Guo, C. -H. 2010. Evaluation of in vitro antioxidant and antibacterial activities of Laminaria japonica polysaccharides. J. Med. Plants Res. 4:2194-2198. Lins, K. O., Bezerra, D. P., Alves, A. P., Alencar, N. M., Lima, M. W., Torres, V. M., Farias, W. R., Pessoa, C., De Moraes, M. O. \& Costa-Lotufo, L. V. 2009. Antitumor properties of a sulfated polysaccharide from the red seaweed Champia feldmannii (Diaz-Pifferer). J. Appl. Toxicol. 29:20-26.

Lustigman, B. \& Brown, C. 1991. Antibiotic production by marine algae isolated from the New York/New Jersey coast. Bull. Environ. Contam. Toxicol. 46:329-335.

Medcalf, D. G. \& Larsen, B. 1977. Fucose-containing polysaccharides in the brown algae Ascophyllum nodosum and Fucus vesiculosus. Carbohydr. Res. 59:531-537.

Nagayama, K., Iwamura, Y., Shibata, T., Hirayama, I. \& Nakamura, T. 2002. Bactericidal activity of phlorotannins from the brown alga Ecklonia kurome. J. Antimicrob. Chemother. 50:889-893.

Nakayasu, S., Soegima, R., Yamaguchi, K. \& Oda, T. 2009. Biological activities of fucose-containing polysaccharide ascophyllan isolated from the brown alga Ascophyllum nodosum. Biosci. Biotechnol. Biochem. 73:961-964.

Nishino, T., Nishioka, C., Ura, H. \& Nagumo, T. 1994. Isolation and partial characterization of a novel amino sugar-containing fucan sulfate from commercial Fucus vesiculosus fucoidan. Carbohydr. Res. 255:213-224.

Niwano, Y., Sato, E., Kohno, M., Matsuyama, Y., Kim, D. \& Oda, T. 2007. Antioxidant properties of aqueous extracts from red tide plankton cultures. Biosci. Biotechnol. Biochem. 71:1145-1153.

Noda, H., Amano, H., Arashima, K. \& Nisizawa, K. 1990. Antitumor activity of marine algae. Hydrobiologia 204/ 205:577-584.

Pereira, M. S., Mulloy, B. \& Mourão, P. A. 1999. Structure and anticoagulant activity of sulfated fucans: comparison between the regular, repetitive, and linear fucans from echinoderms with the more heterogeneous and branched polymers from brown algae. J. Biol. Chem. 274:7656-7667.

Pierre, G., Sopena, V., Juin, C., Mastouri, A., Graber, M. \& Maugard, T. 2011. Antibacterial activity of a sulfated galactan extracted from the marine alga Chaetomorpha aerea against Staphylococcus aureus. Biotechnol. Bioprocess. Eng. 16:937-945.

Raghavendran, H. R., Srinivasan, P. \& Rekha, S. 2011. Immunomodulatory activity of fucoidan against aspirin-induced gastric mucosal damage in rats. Int. Immunopharmacol. 11:157-163.

Shibata, H., Kimura-Takagi, I., Nagaoka, M., Hashimoto, S., Sawada, H., Ueyama, S. \& Yokokura, T. 1999. Inhibitory effect of Cladosiphon fucoidan on the adhesion of Heli- 
cobacter pylori to human gastric cells. J. Nutr. Sci. Vitaminol. (Tokyo) 45:325-336.

Sinha, S., Astani, A., Ghosh, T., Schnitzler, P. \& Ray, B. 2010. Polysaccharides from Sargassum tenerrimum: structural features, chemical modification and anti-viral activity. Phytochemistry 71:235-242.

Tissot, B. \& Daniel, R. 2003. Biological properties of sulfated fucans: the potent inhibiting activity of algal fucoidan against the human compliment system. Glycobiology 13:29G-30G.
Wang, H., Chiu, L. C. M., Ooi, V. E. C. \& Ang, P. O. Jr. 2010. A potent antitumor polysaccharide from the edible brown seaweed Hydroclathrus clathratus. Bot. Mar. 53:265-274.

Witvrouw, M. \& De Clercq, E. 1997. Sulfated polysaccharides extracted from sea algae as potential antiviral drugs. Gen. Pharmacol. Vasc. Syst. 29:497-511.

Yoon, J. -S., Yadunandam, A. K., Kim, S. -J., Woo, H. -C., Kim, H. -R. \& Kim, G. -D. 2013. Dieckol, isolated from Ecklonia stolonifera, induces apoptosis in human hepatocellular carcinoma Hep3B cells. J. Nat. Med. 67:519-527. 